\title{
Reflexiones en torno a la ley de la igualdad entre el hombre y la mujer en la sucesión de los títulos nobiliários
}

Reflections on the law of equality between men and women in the succession of noble titles

\author{
Gerardo de la Puente ${ }^{1}$ \\ UNIVERSIDAD NACIONAL DE EDUCACIÓN A DISTANCIA (UNED) \\ g.puenteortas@gmail.com
}

\begin{abstract}
Recepción: 27/03/16 Revisión: 10/05/16 Aceptación: 16/05/16 Publicación: 01/06/16 http:// (página web de inclusión del artículo)
\end{abstract}

\section{Resumen (máximo 300 palabras)}

La ley 33/2006 de 30 de octubre, sobre igualdad del hombre y la mujer en el orden de sucesión de los títulos nobiliarios, está destinada a favorecer la equiparación en derechos y deberes consagrada por nuestro Texto Constitucional, pero en realidad plantea un buen conglomerado de problemas debido a la existencia de defectos en su configuración.

Este estudio desvela la situación de hombres y mujeres, al tiempo de tramitarse la ley, el proceso de tramitación, las posiciones planteadas en los debates parlamentarios y hace un análisis de las desviaciones existentes y la gravedad de las consecuencias de las mismas.

Palabras clave: igualdad, sucesión, títulos nobiliários, España

\section{Abstract (maximun 300 words)}

Law 33/2006 of 30 October, on equality of men and women in the order of succession of titles, is intended to promote equal rights and duties enshrined in our Constitution, but actually raises a conglomerate problems due to the existence of defects in your configuration.

This study reveals the situation of men and women, while the law of processed, the handling process, the positions stated in parliamentary debates and an analysis of the deviations and the severity of the consequences thereof.

\footnotetext{
${ }^{1}$ Licenciado en Derecho y abogado en ejercicio. Investigador del Grupo de Investigación Historia del Pensamiento Jurídico-Político (GIHPJ_P) de la UNED. Master en Protocolo por la UNED en curso de finalización.
} 
Keywords: Equality, succession, peerages, Spain

\section{Sumario}

1. Introducción

2. Desarrollo

3. Conclusiones

4. Bibliografía

5. Anexo

\section{Summary}

1. Introduction

2. Exposition

3. Conclusion

4. Bibliography

5. Anexed

\section{INTRODUCCIÓN}

Partiendo de la desigualdad existente entre el hombre y la mujer a lo largo de la historia, en todos los ambitos de la vida política, económica, cultural y social, el presente estudio pretende analizar las causas y circunstancias que han provocado la evolución de los valores de la sociedad que han llevado a la igualdad del hombre y la mujer en el trabajo, en el acceso a las fuerzas armadas, en las fuerzas de seguridad del estado y en concreto a la igualdad en el orden de sucesión de títulos nobiliarias mediante la Ley 33/2006 de 30 de octubre. El planteamiento es muy ambicioso, ha sido un camino duro, tenemos que partir de que las mujeres carecían del derecho a votar, han sufrido discriminación en todos los ambitos, el estudio de los antecedentes de la discriminación en todos los aspectos de la vida de la mujer y los logros conseguidos, sería un trabajo suficientemente amplio para escribir varios libros, por ello en el presente estudio nos limitaremos a los antecedentes y a la consecución de la declaración de igualdad en el orden de sucesión de los títulos nobiliarios.

\section{DESARROLLO}

\section{Antecedentes históricos.-}


La discriminación de la mujer en la sucesión de los títulos nobiliarios viene de siglos atrás, en concreto desde las Partidas de Alfonso X, en ellas se establece dos modos para la sucesión en la nobleza. El primero denominado irregular, en el que la Carta de Concesión del título otorgado por el Rey, establece una serie de condiciones muy variables: que solo pueden heredar varones, en casos muy contados solo mujeres, el primer nacido en el momento de la muerte del titular. Es decir dependia del capricho del monarca en el momento de la concesión. El otro, es el de la sucesión regular, que funciona exactamente igual que siempre funcionó la sucesión en la Corona. Esto es; el varón tenía a la hora de suceder preferencia sobre la mujer en igualdad de linea y grado. Este es el caso de nuestro Rey Felipe VI que siendo el menor de tres hermanos, al ser las dos mayores mujeres, él ha heredado el título de Rey.

La Ley $33 / 2006$, de 30 de octubre ha modificado la sucesición de los titulos nobiliarios estableciendo la gualdad entre hombres y mujeres, pero esta ley no afecta a la sucesión en la Corona regulada por una Ley especial. Tanto en la sucesión irregular como en la regular no puede haber discriminación por el sexo del heredero desde la entrada en vigor de la mentada Ley.

A lo largo de los años nadie se había planteado la posibilidad de que heredara un título nobiliario una mujer si habia un varón, y que esta situación era una clara discriminación hacia las mujeres. El marco jurídico de los títulos nobiliarios era muy claro: siempre prevalecía el principio de varonía. El Derecho legal aplicable a las sucesiones nobiliarias estaba integrado por normas preconstitucionales, en las cuales era indiscutible el principio de varonia. Por ejemplo en la Ley de 1820 se establecía que los títulos " subsistirán en el mismo pie y seguirán el orden de sucesión prescrito en las concesiones, escrituras de fundación u otros documentos de su procedencia". Y en el Decreto de 1984 ya en epoca constitucional se establece que " el orden de suceder en todas las dignidades nobiliarias se acomodará estrictamente a los dispuesto en el título de concesión, y en su defecto al que tradicionalemnte se ha seguido en esta materia". Tanto en las Partidas $(2,15,2)$ que regulan la sucesión en la Corona, como en las Leyes de Toro o Pragmaticas referentes a los mayorazgos, se establecía el principio de la varonía, que es aplicado por analogía en la regla sucesoria en las concesiones y documentos. 
Esa situación cambio con el contenido del artículo 14 de la Constitución Española de 1.978, ratificada por los españoles, en el que se establece que " los españoles son iguales ante la ley, sin que pueda prevalecer discriminación alguna por razón de nacimiento, raza, sexo, religion, opinión o cualquier condición o circunstancia personal o social”.

Los títulos nobiliarios responden a una sociedad propia de un momento histórico y de una institución preconstitucional, que tienen dificil encaje en el ordenamiento actual que está presidido por la igualdad de las personas sin distinción por razón de sexo. Con la entrada en vigor de la Constitución, los poderes públicos tienen la obligación de velar por el cumplimiento de los derechos fundamentales y entre ellos el principio de igualdad, según disponen los artículos 9.1 y 53.1 o del nuestro texto Constitucional. El pricipio de igualdad tiene tal trascendencia, que resulta incuestionable su aplicación directa e inmediata a las sucesiones mortis causa abiertas con posterioridad a la Constitución.

Consecuencia directa de ello fue la interposición de numerosos pleitos por primogenitas que consideraban que tenían derecho a heredar el título nobiliario, siendo discriminatorio que lo heredaran sus hermanos menores, al ser ambos iguales ante la Ley.

El Tribunal Constitucional español siempre habia defendido la prohibición de la discriminación, siendo sobre todo en el terreno de la discriminación sexual donde la defensa era más apasionada. A pesar de ello el Tribunal Constitucional ha argumentado la no aplicación del principio de igualdad a la institución nobiliaria, concluyendo que no resulta discriminatoria la preferencia del hombre sobre la mujer en igualdad de linea y grado en materia sucesoria. La primera Sentencia con la que inicia esta linea jurisprudencial es la STC 27/1982, sentando dos afirmaciones, en primer lugar le interesa destacar la supervivencia feudal de los titulos y en segundo lugar el silencio del legislador en la redacción de la Constitución no haciendo mención alguna a los antiguos títulos concecidos antes de la Constitución ni a los que se concedan con posterioridad a ella.

Con esta situación juridica, fue el Tribunal Supremo español, una vez aprobada la Constitución, quién aplicó el principio de igualdad consagrado en la Constitución y que suponía por tanto la derogación de una norma sucesoria preconstitucional creada a tráves de la sucesión regia y reglas y doctrinas sobre mayorazgos. 
La sala I del Tribunal Supremo, en sentencias de 20 de junio, 27 de junio de 1987, " proclama firme y solemnemente, como causa decidendi del recurso y cuestión de fondo en él plantaeada, que en la sucesión de los títulos nobiliarios el principio de masculinidad o preferencia del hombre sobre la mujer, en igualdad de linea y grado, ha de estimarse discriminatorio y en consecuencia abrogado por inconstitucioalidad sobrevenida". Y en otra sentencia de la misma Sala I del tribunal Supremo de 28 de abril de 1989 se establecía que “ la prefrencia del varón <en igualdad de linea y grado> es inconstitucional y por ello fracasará una acción declarativa de mejor derecho a una dignidad nobiliaria, ejercitada despues de entrar en vigor la Constitución fundada en la preferencía del varón sobre la mujer".

A la vista de las mencionadas sentencias del Tribunal Supremo y de la doctrina que en ellas se establecía, resultaba casi impensable que no se concediera la sucesión nobiliaria a las mujeres que lo solicitaran en igualdad de linea y grado. Pero la batalla judicial estaba lejos de terminar, el Tribunal Supremo le daba la razón a las mujeres al considerar que en las normas sucesorias de los títulos se daba una inconstitucionalidad sobrevenida, ya que norma en vigor es la Constitución y no las Partidas de Alfonso X, pero esto cambio a raíz del famoso pleito De la Cierva-Moscoso, en el que el Ilustre jurista Eduardo García de Enterria planteó que si habia o no inconstitucionalidad quien tenía que determinarlo era el Tribunal Constitucional que está creado precisamente para eso y no el Tribunal Supremo.

El Tribunal Constitucional, en una decision que dejó perplejos a la mayoria de los ciudadanos, en la Sentencia 126/1997, de 3 de Julio, le quito la razón al Tribunal Supremo, y estableció que la prevalencia del varón sobre la mujer no tenía, en este caso, nada de inconstitucional, al ser, la esencia de los títulos de nobleza, discriminatoria. El Rey se los da a quien quiere, a unos si y a otros no y sería una paradoja tratar de corregir la discriminación en una norma que es discriminatoria por naturaleza.

Tenemos que indicar que no compartimos los argumentos del Tribunal Constitucional, como bien dice se le otorgan a una persona por un hecho concreto, muerto la persona a la que se concede debería agotarse el título, dado que el título pervive y pasa a los herederos debe reguirse por las normas de las sucesiones, tal y como estan en la actualidad y por el principio constitucional de no discrimación por razón del sexo. No podemos continuar anclados en el pasado donde heredaba el título y los bienes el primogenito varón para salvarguardar el 
patrimonio familiar. Con el paso de los años las normas sucesorias han ido cambiando. Los bienes se reparten entre los herederos, conforme a la legislación aplicable en el territorio al que pertenezca el fallecido, pero el título nobiliario debería corresponder al primer nacido sea varón o mujer conforme a lo establecido en nuestra Constitución al no haber discriminación alguna por razón de sexo. En todo momento el Tribunal Constitucional había denunciado y condenado las prácticas discriminatorias en la que se daba un trato de inferioridad a la mujeres frente a los hombres por el hecho biológico e incuestionable en su condición femenina. Por ello resulta tan sorprendente la orientación que sigue en materia de sucesión nobiliaria, no planteándose si la institución es conforme o no con la Constitución.

El Tribunal Supremo a partir de la STC 126/1997, modificó su doctrina para acatar la linea marcada por la interpretación del Tribunal Constitucional, con lo que todas las sentencias posteriores a la mencionada sentencia han casado las resoluciones de los tribunales inferiores que respetaban el principio de primogenitura sin distinción de sexo para aplicar el principio de varonía.

Dada la trascendencia de la mencionada STC 126/1997, de 3 de Julio vamos analizar con detenimientos los argumentos que Ilevaron al Tribunal Constitucional a perpetuar una discriminación por razón de sexo, que obligó al legislador a la redacción de la Ley 33 /2006 de 30 de Octubre, de igualdad del hombre y la mujer en el orden de sucesión de los títulos nobiliarios.

En la STC 126/1997, de 3 de Julio, se decide sobra " la cuentión de inconstitucionalidad núm 661/96, plantada por la Sección Decimotercera de la Audiencia Provincial de Madrid en relación con el artículo 1 de la Ley de 4 de mayo de 1948, el art. 5 del Decreto de 4 de junio de 1948, el artículo 13 de la Ley Desvinculadora de 1820, las Leyes 8 y 9 del Título XVII del Libro X de la Novísima recopilación, y la Ley 2 del Titulo XV de la Partida II, por supuesta vulneración del artículo 14 C.E”

En los antencedentes de la sentencia se fijan cuales son las normas cuestionadas, reguladoras del orden de sucesión en los titulos nobiliarios:

A) El art. 1 de la Ley de 4 de mayo de 1948, de acuerdo con el cual " se restablecen (,...) las disposiciones vigentes hasta el 14 de abril de 1931 sobre 
concesión, rehabilitación y transmisión de Grandezas y Títulos del Reino, ejercitándose por el Jefe del Estado la gracia y prerrogativas a que aquéllas se refieren"

B) El art. 5 del Decreto de 4 de junio de 1948, norma de rango de Ley por causa de la remisión que ordena el precitado art. 1 de la Ley de 1.948, en la que se dispone que " el orden de suceder en todas las digidades nobiliarias se acomodará estrictamente a lo dispuesto en el título de concesión y, en su defecto, al que tradicionalmente se ha seguido en la material".

C) El art. 13 de la Ley Desvinculadora de 1820, conforme al cual "los títulos, prerrogativas de honor y cualesquiera otras preeminencias de esta clase que los poseedores actuales de vinculación disfrutan como anejas a ellas subsistirán en el mismo pie y seguirán en el orden de sucesión prescrito en las concesiones, escrituras de fundación u otros documentos de procedencia".

D) La Leyes 8 y 9 de Título de la Novísima Recopilación, en la que se establece que " lo qual visto por los de nuestro Consejo y con Nos consultado, fue acordado, que debíamos mandar y declarar, como declaramos y mandamos, que en la sucesión de los mayorazgos, vínculos, patronazgos y aniversarios que de aquí en adelante se hicieren, así por ascendientes como por transversales o extremos, se guarde lo dispuesto en las dichas Leyes de Partidas y Toro".

E) La Ley 2 del Título XV de la Partida II, que establece el orden de sucesión de la Corona y dispone " que el señorio del Reyno non lo oviesse si non fijo mayor después de la muerte de su padre, e este varón siempre en todas las tierras del mundom, doquier que el señorio ovieron por linaje, e mayormente en España. E por escusar muchos males, que acaecieron o podrían ser fechos, pusieron que el Señorio del Rey heredassen siempre aquellos que viniesen por la liña derecha. E por ende establecieron que si fijo varón y non oviesse, la fija mayor heredasse el Reyno...".

El Tribunal Consitucional se centra en la exposición de la duda de constitucionalidad, que tiene por único objeto la vigencia o derogación del principio de varonía. Analizando las discrepancias entre la Jutrisprudencia del Tribunal Supremo que considera derogada el 
principio de varonía, en linea jurisprudencial uniforme desde la sentencia de 20 de junio de 1.987 y la jurisprudencia del Tribunal Constitucional, cifrada en la STC 27/1982, cuyo contenido permite poner en duda que el Derecho histórico haya sido derogado, por cuanto el caracter discriminatorio de los títulos nobiliaros está insito en su propia naturaleza juridical y carece de relevancia constitucional.

En los fundamentos jurídicos de la sentencia el Tribunal Constitucional analiza la concesión de los títulos nobiliarios, su concesión con anterioridad a la constitución, la no regulación de los concedidos ni los que se concedan con posterioridad a la Constución por parte del lesgislador, regulando exclusivamente la sucesión a la Corona, por lo que no entra a estudiar esta institución ni si esta institución es arcaica con los tiempos en los que vivimos, y todo ello le lleva a terminar considerando que los títulos nobiliarios son simbólicos y no introducen un estatus material por lo que no entra a valorar la diferencia de trato por razón de sexo en el orden regular de la sucesión de los mismos. Y por tanto no supone discriminación alguna la primacia de la varonia en la sucesión de los titulos. Lo que le lleva al Tribunal Constitucional en la sentencia analizada a:

"1ㅇ․ Declarar que el art.1 de la Ley de 4 de mayo de 1.948 y el art. 13 e la Ley de 11 de octubre de 1820, en cuanto declaran aplicable el Derecho histórico y en particular, la partida 2.15.2, precepto del que deriva la regla de preferencia del varón sobre la mujer en igualdad de linea y grado, en el orden regular de las transmisiones mortis causa de títulos nobiliarios, no son contrarios al art. 14 C.E, y en consecuencia,

2‥ Desestimar la presente cuestión de inconstitucionalidad".

En la sentencia del Tribunal Constitucional hay un voto particular del Magistrado CRUZ VILLALON que indica "la sucesión se produce en un determinado momento histórico y en un determinado contexto jurídico, y es a ello a lo que hay que atenerse a la hora de regularla no al momento histórico en que se recibió la merced".

La STC 126/1997, de 3 de Julio que declaró que la preminencia de la varonia en la sucesión mortis causa no era inscontitucional al no suponer una infracción de lo dispuesto en el artículo 14 de la Constitución de la igualdad del hombre y la mujer ante la Ley. No zanjo el asunto. Si no que avivo la polémica de la discrimación de la mujer. La jurisprudencia cambio 
pero se continuaron interponiendo demandas raclamando la igualdad del hombre y la mujer en la sucesión mortis causa de los titulos nobiliarios.

El ciudadano no le dió al asunto la importancia y la transcendencia que tenía. Era una disputa por unos títulos de una clase social que para la gente en general esta fuera de su preocupación. A la gente le inquieta que la mujer siga discriminada en el trabajo, en el acceso a los puestos directivos, que tenga una remuneración diferente inferior en razón del sexo aunque realice el mismo trabajo, pero el hecho de que si un determinado título le corresponde a un varón o a una mujer, no les precocupa grandemente, es un asunto para que resuelvan los propios interesados. Nada más lejos de la realidad es otra forma de discriminación fruto de un pasado donde las mujeres erán de una condición inferior al varón no teniendo las mismas posibilidades, por lo que no se puede consentir. El problema ha tardado en resolverse casi una decada al estar el legislador más preocupado en otras cuestiones y debido al escaso interés del resto de los ciudadanos de que al ser una institución del pasado no habia prisa en solucionar.

A pesar de la sentencia del Tribunal Constitucional los pleitos no se terminaron, continuaron las demandas en las que se reclamaba la igualdad del hombre y la mujer en la sucesión de titulos nobiliarios. Ello llevo al Juzgador a la presentación de una proposición de Ley de igualdad del hombre y la mujer en el orden a la sucesión de los títulos nobiliários (número de expediente 122/000162).

2. Debates parlamentarios de la comision celebrado el 29 de junio de 2006 , en la que se aprobo la proposicion de ley una vez debatidas las enmiendas sobre la ley de igualdad entre el hombre y la mujer en la sucesion de titulos nobiliarios.-

La proposición de Ley fue presentada por los Grupos Parlamentarios Socialistas, Popular y Coalición Canaria-Nueva Canaria.

El Sr. Presidente dió comienzo a la sesión recordando el consenso de los tres grupos parlamentarios y que de la Cámara ya hubó célebres defensas de la igualdad del hombre y la mujer en la sucesión de títulos nobiliarios, como la de la ex diputada Cristina Alberdi y otras personalidades, tanto del mundo de la judicatura como del mundo de la doctrina. 
El Sr. Presidente en primer lugar dió la palabra al representante de Coalición Canaria, para la defensa de las enmiendas presentadas.

El Sr. Mardones Sevilla de Coalición Canaria Intervino en la defensa de la enmienda 7 a la Ley, expresando que la retroactividad de la Ley se tenia que ceñir a la fecha sacralizada de 27 de Julio de 2005, fecha de la presentación de Ley en el Congreso de los Diputados, indicando que la retroactividad tenia que circunscribirse a la mentada fecha para evitar la proliferación de litigios y para una concrección del principio de la seguridad juridical a la mentada fecha. Indicaba que habia que dejar los efectos de la retroactividad de la Ley fijada en la disposición transitoria de manera muy clara, indicando que no se aplicarían a otros casos, cualquier resquicio provocaria la invención de la aplicación de la retroacitivadad a otros casos por analogía por justicia o por cualquier otra causa que se le ocurra a los expertos en derecho lo que ocasionaría multiplicar la litigiosidad en los tribunales de justicia, y, sobre todo, considera que el apartado tres de la misma disposisicón, se aplicarán a todos los expedientes relativos a las grandezas de España y títulos nobiliarios pendientes de resolución administrativa o judicial a su entrada en vigor que se hubieran incoado antes del 27 de Julio de 2005, fecha de la presentación en el Congreso de los Diputados de la originaria proposicion, o en los que la sucesión, cesion o distribución como hechos determinantes del expediente se hubiera producido con posterioridad a esa fecha.

El Sr. Presidente a continuación dió la palabra al Grupo Parlamentario vasco (EAJ-PNV), para la defensa de la enmienda número 2.

La señora URIA ETXEBARRIA en nombre del Grupo Parlamentario vasco (EAJ-PNV), defendió la enmienda 2 a la proposición de Ley. Indicando en relación con la proposición de ley que se debate que mantienen el mismo criterio que manifestaron cuando se tomo en cosideración en el Congreso de Diputados, que no tenian interés alguno en participar en su aprobación, su falta de interés se debe a que consideran que es una institución del pasado que debería haber desaparecido.

La señora Uría Etxebarria, defendió su lucha desde siempre por la igualdad del hombre y la mujer. Es una lucha histórica en la que se ha ido avanzando muy despació y le parecía un desproposito empezar regulando la igualdad del hombre y la mujer en la sucesión de los 
títulos nobiliariros, que la inclusión de la igualdad del hombre y la mujer y por tanto la no discrimiación por razón del sexo en el artículo 14 de la Constitución se hizo pensando en buscar la igualdad de oportunidades de los hombres y mujeres en todos los ambitos.

Afirmó de una forma contundente que ni su grupo ni ella misma se identifican con la lucha por la igualdad en la la defensa de acceso a la sucesión de los títulos nobiliarios cuando no hay una igualdad de oportunidades de todos los ciudadanos y ciudadanas en la adquisición de los mismos.

Renegó en nombre de su formación politíca de los títulos concedidos durante el franquismo en donde los méritos para su concesión eran cuestionables, dejando velada su opinion de que tendrían que haber desaparecido con la democracia, por lo que es innecesario entrar a valorar si es necesaria una regulación para evitar la discriminacion en la sucesión de los mismos.

La Señora Uría Extebariria defendió que era más importante la aprobación de le Ley de igualdad, ya presentada en la Camara, y que debería tratarse en un contexto global de igualdad en los aspectos generales de la vida, una igualdad transversal en determinadas materias y quizas detro de este contexto no le hubiese importado dar a su formación política un voto favorable, pero que con el planteamiento de la proposición de Ley debatida en ningún caso pueden dar su voto favorable a la misma.

Una vez dejada clara su postura de que su voto no sería favorable a la aprobación de la propueta de Ley, insisitó en que no debería haberse tramitado como ley independiente, sino dentró de una Ley de Igualdad total entre los hombres y las mujeres en todos los aspectos de la vida. El planteamiento de la Ley y la retroactividad de la misma le parece una propuesta insólita planteada para favorecer los intereses particulares de determinadas personas. Que además deja de tener sentido cuando son numerosas las voces que reclaman la proclamación de la Republica y los valores que se defendieron en ella. Al final termino su discurso como se dice en el argot popular nadando y guardando la ropa, indicando que no les hubiese importado dar su voto afirmativo si fuese una Ley gobal de igualdad entre hombre y mejeres, pero dada la paticularidad de la propuesta que se debate su grupo no se 
opondrá a la tramitación ni a las enmiendas presentadas, pero tampoco darán su voto afrimativo.

El Sr. Presidente continuando con los debates y conforme al orden establecido concedió la palabra a los grupos que desearán fijar su posición, cediendo el uso de la palabra a la representante del grupo Parlamentario Catalán.

La señora Pigem Palmes, por el Grupo Parlamentario Catalán. Defendió que su Grupo mantenia la misma postura en la toma de consideración de la iniciativa, que no era el momento idóneo, que hay otras iniciativas mucho más urgentes que poner encima de la mesa que influyen en la igualdad de hombre y la mujer en el día a día. Considera que son escasas las medidas que todavia hay de conciliación de la vida familiar y laboral, la discriminación salarial, la menor tasa de ocupación de las mujeres, que son la mujeres quienes solicitan en un 99 por ciento la jornada a tiempo parcial, por obligaciones familiares y un largo etcetera que demuestra que el camino por recorrer todavia es muy largo. Se sumo a la manifestaciónes de la portador del Grupo Vasco de ques es necesaria una Ley de Igualdad, y empezarla por la igualdad en la sucesión de los títulos nobiliairios no parece ni lo más lógico ni necesario. Manifestó su preocupación por la inseguridad juridical de la retroactividad de la Ley, lo que ocasionaría un aumento de la litigiosidad. Consideró que la disposisicón transitoria generará muchisimos problemas que cuestionarán y pondrán en tela de juicio el principio de la seguridad juridical y que atentan al principio de la generalidad que deben tener las Leyes. Insistió en que no se puede dotar de retroactividad a una Ley para favorecer a personas con nombre y apellidos, lo cual es claramente contrario al principio de generalidad de las leyes. Consideró que era necesaria una igualdad de hecho y de derecho, también en los títulos nobiliarios pero no consideraba que sea esta Ley la primera que se deba aprobar. Termina manifestando que no apoyaran la iniciativa en los terminos en que esta redactada.

El Sr. Presidente a continuación concede la palabra a la representante del Grupo Parlamentario Popular.

La señora Torme Pardo intervino brevemente reiterando los argumentos que expusieron en los debates que hubo en el Pleno de la Cámara sobre la proposición de Ley, expresando su 
confomidad y el apoyo de su Grupo Parlamentario Popular al informe de la ponencia que hoy se debate, basado en el informe redactado por doña Pilar García Escudero. Indica que son conscientes de la posibilidad del aumento de la litigiosodad con los efectos retroactivos de la Ley y que estan dispuestos a la redacción de un nuevo primer párrafo del punto tercero de la disposición transitoria, con la supresion de la frase que puede dar lugar a un aumento de la litigiosidad. Terminó su intervención diciendo que por nuestra parte, si pudieramos llegar que ese texto fuera más claro para evitar el ultimo apartado del punto tercero de la disposición transitoria, estaríamos totalmente de cuerdo para evitar que hubiera un aumento de la litigiosidad. Explicó que con las enmiendas que se han incorporado el texto se ha mejorado respecto al texto incial de esta proposición de ley, y, reiteró su apoyo al informe elaborado por la ponencia y que apoyarían la proposición de Ley.

El Sr. Presidente concede la palabra a la representante del Grupo Socialista.

La señora Couto Rivas indica que en el día de hoy se términa el debate en el Congreso de una porposición de ley firmada y presentada por tres grupos politicos. Continua manifestando que las intervenciones previas en relación con el texto han levantado numerosas críticas, que su Grupo siempre ha defendido es esta proposición el principio de igualdad entre hombre y mujer. No es acaeptable que se produzca una discriminación porque hay una preferencia del principio de varonía sobra la mujer, y por ello su Grupo siempre que haya una discriminación actuarán defendiendo el principio de igualdad. Que la aprobación de la proposición de la Ley de la igualdad en la sucesión de tírulos nobiliarios entre el hombre y la mujer, y su repercussion en la sociedad en general es un pequeño avance en la igualdad, pero que tienen que tomarse como un revulsivo para continuar avanzando en el largo camino que que queda por recorrer hasta alcanzar una igualdad de hecho y de derecho entre los hombres y las mujeres.

Al igual que la representante del grupo Popular ratificó el informe de la ponencia para analizar una a una las enmiendas dando las razones por las que las apoya y el motivo por las que las rechaza, explicó que presentaron un texto alternativo a la enmienda número 9, al artículo 2, dado que declarar la nulidad de las previsiones de la Real Carta eso daría lugar a la revisión de toda la historia de las sucesiones nobiliarias, que provocaria una inseguridad juridical que no se pretende con la presente ley. Rechazó la enmienda número 7 de Coalición 
Canaria y la número 2 del Grupo Parlamentario Vasco. Terminó reiterando su apoyo al texto de la enmienda y que la presente proposición de Ley supone un avance en la lucha contra la discrimacioón de las mujeres, aunque sea de un reducido grupo.

Terminada la intervención de la Señora Couto Rovas solicita la palabra el señor Mardones Sevilla.

Concedida la palabra por el Sr. Presidente el Sr. Mardones Sevilla del Grupo Socilaista solicita que se voten los artículos uno a uno al ser solamente dos, al igual que las disposiciones derogatorias y transitorias.

El Sr. Presidente concede seguidamene la palabra ala señora TORME PARDO del Grupo Parlamentario POPULAR, que indica que dadas las discrepancias del punto 3 de la disposisicón transitoria, propone una mejora técnica e interrumpir unos minutos el debate para que sea estudiada, la mejora es " Las disposiciones de esta Ley se aplicarán a todos los expedeintes relativos a grandezas de España y títulos nobiliairos pendientes de resolución administrativa o judicial a su entrada en vigor que se hubieran incoado antes del 27 de Julio de 2005, fecha de la presentación en el Congreso de los Diputaods de la originaria proposición de ley, o en los que la sucesión, cesión o distribución como hechos determinantes del expediente se hubieren producido con posterioridad a esa fecha", Manteniendo el resto del punto tercero.

El Sr. presidente indica que le parece muy positivo que se abra un periodo de reflexión e incluso dejar la decision para el mes de septiembre. Una vez consultados los diferentes grupos parlamentarios sobre el asunto se concede la palabra a la señora COUTO RIVAS que mantiene el texto del informe de ponencia.

El Sr. Presidente a continuación indica que a la vista del acuerdo de todos los grupos se procede a la votación de esta proposición histórica.

Se someten a votción en primer lugar la emnienda 7 del Grupo Parlamentario de Calicion Canaria-Nueva Canarias y la enmienda 2 del Grupo Parlamentario Vasco, siendo ambas enmiendas rechazadas. 
El Sr. Presidente a continuación somete a votación los artículos 1 y 2 de la Ley, la disposición derogarotia, la disposición tranistoria, y la disposición final segunda, que luego pasará a ser la primera y la disposición final tercera que pasará luego a ser la segunda y finalmente la exposición de motivos.

Sometido a cotación el artículo 1 fue aprobado por unanimidad, el articulo 2, fue aprobado por 34 votos a favor y una abstención, la disposición transitoria fue aprobada por 32 votos a favor, dos votos en contra y una abstención. Se aprobo por unanimidad la supresión de la disposisicón final primera, que la ponencia ya habia declarado su supresión, se aprobó por unanimidad la disposición adicional segunda, la disposición adicional tercera fue aprobada por 34 votos a favor y una abstención y por ultimo la exposición de motivos fue aprobada por 33 votos a favor y dos abstenciones.

Termino manifestando el Sr. Presidente que con esta votación queda dictaminado y aprobado con competencia legislativa plena esta proposición de Ley.

En resumidas cuentas todos los grupos estaban deacuerdo en que cualquier discriminación de la mujer es intolerable, luego cada Grupo Parlamentario aprovecha la ocasion de hacer su discurso en funcion del Grupo al que pertenece. Lor Grupos Parlamentarios proponentes dejan claro que era una necesidad social y que se no podia esperar más, el resto de los Grupos no entienden las prisas, si ya se habia presentado en la Camara la ley de igualdad y además consideran que la introduction de la retroactividad de la Ley a una fecha determinada es para beneficiar a una serie de personas en concreto y que atenta contra la seguridad juridica y el principio de generalidad que deben tener todas las Leyes. Dado que se quiebra el principio de la irretroactividad de las leyes, puestos podían haberla retrotraido a la fecha de la aprobación de la constitución en la que se define la igualdad de los hombre y las mujeres.

\section{Ley $33 / 2006$, de 30 de octubre, sobre igualdad del hombre y la mujer en el orden de sucesion de los titulos nobiliarios.}

La exposición de motivos de la Ley recoje la teoria del Tribunal Constitucional de que la posesión actualmente de un título nobiliario no otorga ningún privilegio, es una distinción honorifica, cuyo derecho se agota en usarlo y protegerlo contra terceros. 
Continua la exposición de motivos indicando que su caracter de concesión perpetua, sirve para mantener el recuerdo histórico al que se debe su otorgamiento y que la mencionada distición esta vinculda a las personas de un linaje determinado. Esto es lo que justifica su pervivencia en la actual sociedad demócratica. Pero que es necesario acomodar las normas que regulan la sucesión a los tiempos actuales suprimiendo la discriminación de las mujeres integradas totalmente y participando plenamente en la vida polictica, económica cultural y social.

La plena igualdad de los hombres y las mujeres en todas las esferas jurídicas y sociales fue reconocida en la Convención para al Eliminación de Todas las Formas de Discriminación contra la Mujer, adoptada en Nueva York el 18 de diciembre de 1.979, y ratifica por España en 1.984 .

Concluye la exposición de motivos indicando que si las funciones de los títulos nobiliarios son meramente representativas y simbólicas, pueden ser desempeñadas de igual forma por los hombres que por las mujeres, no teniendo sentido alguno la discriminación por razón de sexo.

Si echamos la vista atrás unos siglos la discrimanción estaba plenamente justificada, era otra epoca y primaban otros valores, que a nosotros nos pueden parecer injustos, abominables pero que eran parte de la sociedad y no eran cuestionados. Por ello la concesión de los títulos y la sucesión de los mismos iba pareja a la condición de la varonía, pero ello era consecuencia directa de los tiempos, quienes iban a las guerras, quienes detentaban el poder, a las mujeres les estaba vetado no solo el derecho de voto, en muchos casos la posibilidad de aprender a leer. No queremos ahondar más en la discriminación que sufrían pues ello nos llevaria a la mayor aberración de la posibilidad de su venta como esclavas o el derecho de pernada del noble sobre sus subditos. Barbaridades que parecen increibles pero que si hojeamos la historia a través de los libros y documentación de aquellas epocas eran asumidas por todos.

En el artículo 1, se declara la igualdad del hombre y la mujer en el derecho a suceder en las Grandezas de España y títulos nobiliarios, sin que pueda utilizarse el sexo para variar el orden regular de os llamamientos. 
En el artículo 2, se afirma que dejan de surtir efecto las previsiones de la Real Carta de concesión del título que excluyan a las mujeres o establezcan una prevalencia del varón en igualdad de linea y de grado. Encomendando a los jueces y tribunales el cumplimiento de lo aprobado en este artículo.

En la disposición transitoria única es donde el legislador ha efectuado malabares:

En su apartado primero indica que las trasmisiones de títulos ya acaecidas no se reputarán invalidas por haberse realizado al amparo de la legislación anterior.

En el apartado segundo se trata sobre la rehabilitación de un título nobiliario vacante, indicando que se reputarán validas las trasmisiones efectuadas conforme a la legislación anterior hasta su ultimo poseedor, debiendo aplicarse la ley actual, debiendo acreditarse el parentesco de quien lo solicite.

Hasta aqui las disposiciones transitorias son las normales y habituales, son validas las sucesiones nobiliarias efectuadas con la legislación anterior. Donde surge el problema y la controversia es con el apartado 3, que trascribimos literalmente " No obstante lo previsto por el apartado 1 de esta disposición transitoria, la presente Ley se aplicará a todos los expedientes relativos a Grandeza de España y títulos nobiliarios que el día 27 de Julio de 2005 estuvieran pendientes de resolución adminisrativa o jurisdiccional, tanto en la instancia como en vía de recurso, asi como a los expedientes que se hubieran promovido a partir de aquella fecha, en la cual se presentó la originaria proposición de ley en el Congreso de los Diputados. La autoridad administrativa o jurisidiccional ante quien penda el expdiente o el proceso concederá de oficio trámite a las partes personadas a fin de que aleguen lo que a su derecho convenga de conformidad con la nueva Ley en el plazo común de cinco días".

En el apartado cuarto se exceptuan de la aplicación de lo previsto en el apartado anterior a aquellos expedientes en los que haya reacído sentencia firme a la entrada en vigor de la presente Ley.

Es decir que se premía a las autoridades lentas, tribunales ociosos y ciudadanos que por sus recursos puedan seguir litigando, interponiendo todo tipo de surterfugios para que diera tiempo a entrar en vigor la Ley. 
En ningún caso se debería aplicar la retroactividad de la Ley, pero si se aplica al considerar que es un derecho fundamental, se debe aplicar a todos los asuntos por igual sin distición, llevando la retroactividad al mismo momento de la aprobación de la Constitución y del tan debatido artículo 14. No estamos hablando de unos titulos nobiliarios que no otorgan ningún privilegio, que son una mera distincion honorifica, de caracter simbólico que solamante dan derecho a un tratamiento, que más da que lo détente un hombre o una mujer, el cambio no influira en la seguridad juridica, ya que según el planteamiento del Tribunal Constitucional y de la misma Ley no produce ningún efecto jurídico el uso de los mencionados títulos.

La aplicación de la retroactividad de la Ley ha dado lugar al planteamiento de numerosas demandas cuestionando la validez de la cesion efectuada en vida de titulos nobiliarios con discriminación de sexo. Cesiones efectuadas algunas de ellas con anterioridad incluso a la propia Constitución, al amparo de la disposición transitoria tercera de la Ley 33/2006 de 30 de octubre sobre igualdad del hombre y la mujer en el orden de sucesión de los titulos nobiliarios. Las sentencias consideran nulas las cesiones efectuadas en perjuicios de terceros que tenian mejor derecho a suceder, los cuales no dieron su consentimiento a la cesion del título efectuada.

Entre las sentencias mencionamos:

1a La Sentencia del Tribunal Supremo 1986/2014, Sala de lo Contecioso Administrativo, de 19 de mayo de 2014, en este caso se trata de una cesion efectuada el 24 de octubre de 2006 unos días antes de que entrara en vigor la Ley 33/2006 de 30 de octubre. Se declara nula la cesion efectuada al no haber dado su consentimiento la hermana mayor a la que le correspondía la sucesión del título

2a La Sentencia del Tribuanl Supremo 2897/2011 Sala de lo Civi, de 7 de Julio de 2014, en este caso nos encontramos con la cesion de un título de Conde efectuada el 21 de diciembre de 1971. Se declara nula la cesion efectuada y se concede el derecho a la primogenita.

3a En el mismo sentido se ha pronunciado el Tribunal Constitucional, en la que se declara nula la cesion de título nobiliario realizada en escritura pública el 22 de octubre de 
1984, al no haber dado su consentimiento expreso la tercera perjudicada que tenia menor derecho en la sucesión del mencionado, título.

Como vemos la retroactividad de la Ley 33/2006 de 30 de octubre, esta llegando mucho más lejos de lo que en principio pensaron los propios proponentes de la Ley y ello es consecuencia de que queda al arbitrio de los tribunales de justicia la interpretación de las leyes en todo aquello que no se recoja expresamente en las Leyes.

\section{CONCLUSIÓN}

Este trabajo ha pretendido hacer un análisis del gran avance que en la igualdad del hombre y la mujer ha supuesto la Ley 33/2006 de 30 de octubre, en las conclusiones modestamente hacemos referencia a los logros conseguidos e incidimos en que queda mucho camino que recorrer para conseguir la ansiada igualdad de derecho y de hecho, proponiendo actuaciones que deben redundar con el tiempo a estar más cerca de la misma.

10 La discriminación del hombre y la mujer es una constante a la largo de la historia de la humanidad, nos hemos fijado en la sucesión de los títulos nobiliriaros pero la discriminación es patente desde siempre.

20 Los avances en la lucha contra la discrimación entre el hombre y la mujer han sido muchos a lo largo de los años, la concesión del derecho al voto, la posibilidad incorporarse a los cuerpos de seguridad del estado, al ejercito, a la politica, al trabajo en general.

3은 La Ley 33/2006 de 30 de octubre, sobre igualdad del hombre y la mujer en el orden de sucesión de los títulos nobiliarios, a los ojos de muchos supone un pequeño logro al afectar a una determinadas clases sociales y a un numero reducido de mujeres. Tenemos que indicar que se equivocan los que piensan que no tiene una gran trascendencia, ya que supone la declararación de igualdad de la mujer para el acceso a un estatus reservado casi exclusivamente para los hombres y que han defendido con todas las armas a su alcance, como si se tartara de un club del cual los socios solamente pueden ser hombres.

40 Poco despues se aprobó la Ley de la lgualdad entre los hombres y las mujeres en todos los ambitos, que supuso un gran paso en la lucha por llegar a una igualdad de hecho no solo de derecho. 
5o Aunque tenemos las mencioandas Leyes que declaran la no discriminación por razón de sexo, la igual del hombre y la mujer, en el día a día, continuamos viendo que esta discriminación existe, con sueldos más bajos por la condición femenina, la no contratación de mujeres en determiandas empresas por no tener que soportar las bajas por maternidad, las multiples dificultades que tienen para el acceso a cargos de responsabilidad y sin ir más lejos, cuantas mujeres son catedraticas en la universidad, podiamos seguir poniendo ejemplos de la desigualdad que sigue padeciendo las mujeres de hecho, aunque las Leyes digan lo contrario.

6o Para llegar algún día a la soñada igualdad entre hombres y mujeres, hay que cambiar la mentalidad de la sociedad, inculcar a los niños que tienen diferencias biologicas, pero que son personas iguales, con ello quizas consigamos erradicar uno de los males mayores de esta sociedad como es la violencia de género, consecuencia directa de la mentalidad del hombre de considerar que la mujer es inferior, es casi una propiedad.

\section{BIBLIOGRAFÍA}

- $\quad$ Asociación Nobiliaria Española, http://www.asociacionnobiliaria.com/faq.htm

- $\quad$ ARNALDO ALCUBILLA, Enrique, "Régimen transitorio de la Ley 33/2006 de 30 de octubre, sobre igualdad del hombre y la mujer en el orden de sucesión de los títulos nobiliarios", La Ley: Revista juridical española de doctrina, jurisprudencia y bibliografía, no 4 (2007), pp. 1353-1357.

- Blog de Heraldía, "Retorno a la nobiliaria", 27 de abril de 2009, http://blogdeheraldica.blogspot.com.es/2009/04/retorno-la-nobiliaria-i-la-ley-332006.html consultado el 16/01/2015

- Derecho nobiliario, www.derechonobiliario.com

- $\quad$ DÍAZ-BASTIEN, Ernesto. "La sucesión en los títulos nobiliarios y la retroactividad de las leyes", en http://www.diazbastientruan.com/2014/02/la-sucesion-en-los-titulos-nobiliariosy-la-retroactividad-de-las-leyes/, consultado el 15 de enero de 2015.

- Doscientos nobles piden amparo al Rey para defender la tradición nobiliaria, El confidencial, 06/07/2009

- Heraldia catalana, http://heraldicacatalana.blogspot.com.es/2010/07/la-ley-332006de-30-de-octubre.html

- HIDALGO, Javier, "La igualdad en el orden de sucesión de títulos nobiiarios", foro debate en http://www.heraldaria.com/phorum5/read.php?3,2831,2853, consultado el 10 de enero de 2015.

- $\quad$ LÓPEZ VILAS, Ramón, El Nuevo Derecho nobiliario, Tirant Lo Blanch, 2009.

- MARTELO DE LA MAZA GARCÍA, Marcial, La sucesión nobiliaria, Madrid, Dikinson, 2013.

- ROGEL VIDE, Carlos y DÍAS-BASTIEN, Ernesto, En torno a la sucesión en los tíruclos nobiliarios, Madrid, Reus, 2012. 
- $\quad$ TORRES, Concep, "La aplicación de la Ley 33/2006, de 30 de octubre, sobre igualdad en los títulos nobiliarios", Género y derechos Humanos, http://www.genero.juristconcep.com/index.php?option=com_content\&view=article\&id=47: la-aplicacie-la-ley-332006-de-30-de-octubre-sobre-la-igualdad-en-los-tlosnobiliarios\&catid=3:destacamos consultado el 10/01/2015.

\section{ANEXO}

\section{Legislación nobiliaria}

- Ley II, Título XV de la Partida II

- Leyes XL, XLI, XLV y XXV de Toro.

- Ley de 17 de junio de 1855, aclarando el art. 13 de la de 11 de Octubre de 1820 sobre vinculaciones.

- Ley de 5 de diciembre de 1899 , disponiendo que, á partir de la promulgación de la misma, comiencen á regir nuevas tarifas para la exacción del impuesto especial sobre grandezas, títulos, honores y condecoraciones.

- Real Decreto de 7 de enero de 1901, por la que se aprueba un nuevo Reglamento para el Ministerio de Gracia y Justicia con arreglo a la Ley de 19 de octubre de 1889.

- Real Orden de 26 de julio de 1901, referente á la tramitación de expedientes, anuncios de vacantes y declaración de caducidad de los títulos del Reino.

- Ley de Presupuestos de 26 de diciembre de 1914 para el año 1915, contiene rango de Ley a la legislación anterior sobre caducidades y expresamente al Real Decreto de 27 de mayo de 1912.

- Orden de 7 de marzo de 1918, reglamentando el derecho a obtener certificaciones y devoluciones de documentos presentados por los particulares en los expedientes relativos a Títulos nobiliarios y Grandezas de España

- Ley de 5 de agosto de 1918, reformando las disposiciones relativas al Timbre del Estado, comprendidas en las Leyes de 1906 y 1910, con referencia al timbre en la creación y sucesión de Títulos Nobiliarios.

- Real decreto de 29 de mayo de 1922, relativo a inscripciones y anotaciones en el Registro civil de la Real Familia de España, y creando un Registro civil especial para la inscripción y anotación de actos del estado civil de personas que tengan la cualidad de Principes Reales de las Casas ligadas por vínculos de parentesco de consaguinidad o afinidad con la del Rey de España.

- Circular de la Fiscalía del Tribunal Supremo de 27 de noviembre de 1922, resolviendo algunas dudas acerca de la ley sobre supresión de pagos

- Decreto disponiendo queden suprimidas las Ordenes Militares de Santiago, Montes, Alcántara y Calatrava; declarando disuelto el Tribunal de las Ordenes Militares, y cambiando la denominación de las Maestranzas de Sevilla y Ronda.

- Constitución de la República española de 1931

- Ley de 4 de mayo de 1948, por la que se establece la legalidad vigente con anterioridad al 14 de abril de 1931 en las Grandezas y Títulos del Reino

- Decreto de 4 de junio de 1948, por el que se desarrolla la Ley de 4 de mayo de 1948 sobre Grandezas y Títulos nobiliarios

- Decreto de 4 de junio de 1948 por el que se declara de aplicación la Tarifa 1. a contenida en la Ley reguladora del Impuesto sobre Grandezas y Títulos, Condecoraciones y Honores, texto refundido de 2 de septiembre de 1922, así como 
las disposiciones y normas complementarias contenidas en la misma en cuanto no se opongan a lo dispuesto en este Decreto

- Rectificación al Decreto de 4 de junio de 1948, que declaraba de aplicación la tarifa 1a. contenida en la ley reguladora de Impuesto sobre Grandezas y Títulos. Condecoraciones y Honores, texto refundido de 2 de septiembre de 1922, así como las disposiciones y normas complementarias contenidas en la misma en cuanto no se opongan a lo dispuesto en este Decreto

- Decreto-Ley de 9 de julio de 1948, sobre impuesto de Timbre en las concesiones de Títulos y Grandezas

- Orden de 27 de octubre de 1948, por la que se dictan normas complementarias a la disposición transitoria primera del Decreto de 4 de junio de 1948

- Orden de 12 de diciembre de 1948, por la que se prorroga el plazo concedido para instar la confirmación de expedientes en curso en 14 de abril de 1931 o para convalidar las sucesiones tramitadas por la Diputación de la Grandeza

- Ley de 23 de diciembre de 1948 sobre reconstrucción de la documentación familiar destruida por el saqueo o incendios de los archivos particulares patrimoniales en la Guerra de Liberación

- Orden de 8 de enero de 1949 por la que se dictan normas para la ejecución de la Ley de 23 de diciembre de 1948 sobre la reconstrucción de la documentación familiar destruida por el saqueo o incendio de los archivos patrimoniales en la Guerra de Liberación

- Orden de 4 de febrero de 1949, acordada en Consejo de Ministros aclaratoria de las normas que regulan el pago sobre el impuesto de Títulos y Grandezas del Reino

- Orden de 17 de marzo de 1950, acordada en Consejo de Ministros, por la que se dictan normas para el cómputo de plazos a efectos el ingreso en el Tesoro de las liquidaciones que se practiquen por el impuesto sobre Grandezas y títulos del Reino

- Ley de 9 de mayo de 1950, sobre modificación del artículo 322 del Código Penal en relación con el uso indebido de títulos nobiliarios

- Decreto de 5 de junio de 1950 por el que se dictan normas para la aplicación del Impuesto sobre Grandezas y Títulos

- Decreto de 13 de abril de 1951 por el que se regulan las funciones de los Cronistas de Armas

- Decreto de 28 de marzo de 1952 sobre impuesto de Títulos y Grandezas concedidos por los Monarcas de la Rama Tradicionalista

- ORDEN de 4 de mayo de 1956, por la que se manda publicar la Guía Oficial de la Grandeza y Títulos del Reino en uso legal

- Decreto 1453/1960, de 7 de julio, por el que se aprueba el texto refundido de la Ley reguladora del Impuesto sobre Grandezas y Títulos Nobiliarios, Honores y Condecoraciones (abreviadamente Impuesto sobre Títulos y Honores)

- Decreto 1299/1960, de 1 de junio, por el que se establecen normas sobre peticiones de rehabilitación de títulos nobiliarios

- Convenio suprimiendo la exigencia de la legalización de los documentos públicos extranjeros, hecho en La Haya el 5 de octubre de 1961

- Ley 41/1964, de 11 de junio, de Reforma del Sistema Tributario

- Convenio número 17 de la Comisión Internacional del Estado Civil (CIEC) 
- Decreto-Ley $17 / 1975$, de 20 de noviembre de 1975, sobre restablecimiento del Registro del Estado Civil de la Familia Real de España.

- Real Decreto 2433/1978, de 2 de octubre

- Orden de 30 de diciembre de 1978 por la que se interpreta y desarrolla el Real Decreto 2433/1978, de 2 de octubre, sobre supresión de legalizaciones en relación con los países vinculados por el Convenio de La Haya de 5 de octubre de 1961.

- Constitución española de 27 de diciembre de 1978.

- Real Decreto 602/1980, de 21 de Marzo, por el que se modifican diversos artículos del Real decreto de 8 de Julio de 1922

- Ley 34/1980, de 21 de junio, de Reforma del Procedimiento Tributario. (Vigente hasta el 1 de julio de 2004).

- Real Decreto Legislativo 3050/1980, de 30 de diciembre

- Instrumento de Ratificación de 27 de enero de 1981 del Convenio número 17 de la Comisión Internacional del Estado Civil, sobre dispensa de legalización de ciertos documentos, hecho en Atenas el 15 de septiembre de 1977.

- Real Decreto 569/1981, de 27 de marzo, por el que se prorroga el plazo concedido por la disposición transitoria del Real Decreto 602/1980, de 21 de marzo

- Real Decreto 2917/1981, de 27 de noviembre, sobre Registro Civil de la Familia Real

- Instrumento de ratificación de 30 de enero de 1980 del Convenio número 16 de la Comisión Internacional del Estado Civil sobre expedición de certificaciones plurilingües de las actas del Registro Civil, hecho en Viena el 8 de septiembre de 1976 («BOE núm. 200/1983, de 22 de agosto de 1983»)

- Real Decreto $1368 / 1987$, de 6 de noviembre, sobre régimen de títulos, tratamientos y honores de la Familia Real y de los Regentes

- Real Decreto 222/1988, de 11 de marzo, por el que se modifican los Reales Decretos de 27 de mayo de 1912 y 8 de julio de 1922 en materia de Rehabilitación de Títulos Nobiliarios

- Real Decreto 1879/1994, de 16 de septiembre.

- Real Decreto 828/1995, de 29 de mayo de 1995, por el que se aprueba el Reglamento del Impuesto sobre Transmisiones Patrimoniales y Actos Jurídicos Documentados .

- Providencia de 14 de marzo de 1996, cuestión de inconstitucionalidad número 661/96.

- Orden de 8 de octubre de 1999 por la que se dispone la publicación de los Estatutos de la Diputación Permanente y Consejo de la Grandeza de España.

- Ley 33/2006, de 30 de octubre, sobre igualdad del hombre y la mujer en el orden de sucesión de los títulos nobiliarios.

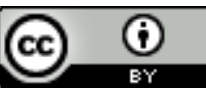

This work is licensed under a Creative Commons Attribution 3.0 Unported License 